\title{
JOSEP FONTANA: RECUERDOS DE UN AMIGO, LECCIONES DE UN MAESTRO
}

\author{
José Daniel Gil Zúñiga*
}

Corría la mitad de los años 1980. Había leído una de las primeras obras suyas que llegó a nuestro país, Historia. Análisis del pasado y proyecto social. En ella un autor que por entonces estábamos apenas conociendo, hacia una lectura crítica de la evolución de la historia como quehacer desde la antigüedad hasta nuestros días, y al hacerlo, iba dibujando la clara relación entre quienes tenían el poder y la forma de comprender la historia en cada una de las épocas analizadas. Con claridad meridiana, nos invitaba a una clase de historiografía que se apartaba, y mucho, de lo que yo había entendido como tal en las aulas de la Escuela de Historia de la Universidad Nacional, en Heredia, Costa Rica. ${ }^{1}$ Entre ambas concepciones existía una distancia del cielo a la tierra, y la suya me captó desde las primeras páginas. Más tarde vino la lectura de artículos dispersos.

Era el año de 1986, y decidí que ya era tiempo de hacer las maletas e ir por un doctorado. Había apostado por ir a Rumania a estudiar en la Universidad de Cluj en la rama de historia económica. Fui a la embajada en Rohrmoser y me atendió un pintoresco embajador. Gracias a Dios no saqué nada de dicha visita, pues aunque cada vez reconozco más el peso condicionante de lo económico, sigue sin atraerme el estudio de las variables estrictamente económicas. Quise ir a París y tampoco se pudo, el gobierno francés, justo por esos años no concedía becas para

* Costarricense. Doctor en Historia por la Universidad Autónoma de Barcelona, España. Correo electrónico: jodagizu@gmail.com

1 Esa preocupación por la historiografía estaría presente a lo largo de su obra y se mostraría con mucha claridad en trabajos como el ya citado en este párrafo y en otras que escribiría a posteriori. Cfr. Josep Fontana i Lázaro, Historia. Análisis del pasado y proyecto social (Barcelona, España: Editorial Crítica, 1982). Existe una versión más actualizada de esta obra y publicada por la misma casa en 1999. Josep Fontana i Lázaro, La historia después del fin de la historia (Barcelona, España: Editorial Crítica, 1992) e Introducción al estudio de la historia (Barcelona, España: Editorial Crítica, 1992). En todas ellas exhibe una claridad de pensamiento y aunque están escritas para un público especializado, estas obras pueden ser leídas por personas y profesionales no formados como historiadores. Ese era uno de sus atributos: él se daba a entender, quería ser útil socialmente y sabía que solo lo sería si escribía lo complejo en términos muy sencillos. Eso facilitó la difusión de su pensamiento 
que un costarricense fuese a estudiar a ese país. Justo en esos momentos comenzaba mi entronque, a través de la lectura con quien sería luego un buen maestro y amigo y enfoqué mis esfuerzos en irme a la Ciudad Condal.

Alentado por mi tutor de tesis, el Dr. Héctor Pérez Brignoli, en la mañana del 10 de abril de ese mismo año, tomé el teléfono en casa de mi hermana y llamé a alguien de quien solo conocía algunos trazos de su pensamiento. De entrada me atendió otra persona y me pasó con él. Me atendió en castellano. Me presenté y le expliqué el motivo de mi llamada, y me contestó que encantado me recibiría bajo su tutela. Le pedí una carta en la que indicara que me admitía como su estudiante en la Universidad Autónoma de Barcelona (UAB), explicándole que la misma era vital para que me dieran la beca. Anotó mis datos y mi dirección y una semana después tenía yo su misiva en mis manos. El mismo día que le llamé, escasa una hora después, pedí una nota en el Departamento de personal de la Universidad Nacional (UNA) en la que se certificara que yo era docente en dicha institución. ¡Llegó primero la nota de mi buen amigo de Barcelona, que la de la universidad que tenía que atravesar la calle! Eso retrata de cuerpo entero a la persona de la cual quiero hablar en estas páginas, un hombre solidario, entregado a sus estudiantes. Ese año no me dieron la beca, pero si al año siguiente, y me fui a Barcelona, con una beca del Instituto de Cooperación Iberoamericana, una ayuda exigua de la UNA, y el invaluable apoyo paterno.

Inicios de octubre de 1987. Habíamos pactado una reunión en Bellaterra en el Departamento de Historia Moderna y Contemporánea de la UAB. Llegué antes que él, busqué el departamento, ubiqué su oficina y me senté en una silla como tonto sin mama, al final del pasillo. Yo esperaba ver un gran letrero que anunciara su nombre y lo que había era una pequeña y muy sencilla placa con su nombre: Josep Fontana i Lázaro. Yo lo había imaginado pequeñito, gordo, calvo y con unos lentes tan gruesos como el fondo de una gaseosa. Al rato apareció un señor de mediana estatura, bigote recortado, lentes bifocales, con pelo y de complexión y estatura regular jéste no es el profesor me dije! Y seguí allí sentado, apretujado en una silla al fondo del pasillo. Comenzó a llegar y salir gente, y yo allí, sin moverme. Me decía: ¡alguno de esos tiene que ser el profesor Fontana!

Pasaron los minutos, las horas qué se yo. Hubo un momento en que se abrió la puerta y se asomó él, sacando apenas la mitad del cuerpo, me vio y me preguntó ¿busca usted a alguien? A lo que yo respondí "Busco al Profesor Fontana", él respondió "Soy yo", y acto seguido me invitó a pasar. Les juro que sentado ante él, recordé otra mañana, años antes, que sentado en la oficina de la Decanatura de Ciencias Sociales de la Universidad de Costa Rica (UCR), me reuní por primera con don Héctor Pérez Brignoli con el objetivo de trabajar mi tesis de licenciatura. Estando delante de Josep, me temblaba hasta el alma. Yo estaba allí, sentado frente al gran historiador catalán. 
Ni les cuento detalles de ese día. Desde el primer momento me encontré con alguien que me exigió que le tratara de igual a igual. No se me olvida su decir: "Entre tu y yo no hay diferencias, somos dos seres humanos". A los pocos días volvimos a vernos, le entregué uno de los trabajos que había escrito sobre la delincuencia en Heredia y dos días después, con una dureza formadora, esa que solo tienen los maestros, destrozaba sin humillarme mi trabajo. ¡Esa sesión no la voy a olvidar nunca! Me prometió que en dos días me traería bibliografía para que comenzáramos a trabajar y efectivamente en tal plazo, tenía ante mí libros que él había fotocopiado. Aún guardo esas viejas fotocopias.

Ese era y sigue siendo en algún lugar donde esté, mi amigo Josep Fontana. Durante mi estadía en Barcelona, un profesor de la Autónoma me indicó que en la Biblioteca de dicha universidad, 40.000 volúmenes eran de su propiedad y que él los ponía allí para que los estudiantes de historia leyéramos. Si se los rayaban, mutilaban o robaban, no pasaba nada, lo importante es que nosotros leyéramos.

Bajo su tutela armé mi programa doctoral, unas materias en la Autónoma, otras en la Universidad de Barcelona. Me decía "Matricúlate con este, allí vas a aprender mucho", y así fue como conocí profesores con los cuales construí una hermosa amistad y de los cuales he aprendido mucho: el Dr. Ricardo García Cárcel, un mentor para mí, el Dr. Joan Bestard Camps del cual me sedujo su enfoque antropológico, ambos verdaderos maestros a los cuales debo mucho en esos años de estudios doctorales y aún en el curso de los siguientes. Sumo a la Dra. Josefina Roma i Rius quien me adentró en un campo que cada vez me seduce más, el de los cuentos y las leyendas, y su impronta en la historia de un país, conocí también a un sociólogo de lo penal argentino el Dr. Roberto Bergalli y al penalista chileno el Dr. Juan Bustos Arratia, un auténtico caballero. Si en las clases de Bergalli se conocían anécdotas y se introducía uno en la criminología con don Juan uno se zambullía con goce y entretenido en las teorías del control social. De él aprendí mucho sobre este campo y saque lecciones invaluables de su humanidad. Josep me introdujo en los cursos de estos profesores, fue bajo su guía y por gusto personal que los matriculé. Él supo quién podía contribuir en mi formación, tenía la humildad de saber hasta dónde podía llegar él. No se consideraba un vasto conocedor de la historia de nuestro continente y por eso me recomendó que buscará al Dr. Carlos Martínez Shaw, me habló de él como un reconocido americanista, y aunque no tomé ninguna materia con él, con el paso del tiempo hemos podido entre él, su esposa Marina Alfonso Mola y yo construir una hermosa y cálida amistad de la cual me precio. ${ }^{2}$

2 Carlos Martínez Shaw ha escrito la mejor reseña en homenaje a Josep Fontana que he leído en estos días en la prensa española. Claro, sintético, mesurado. Quien quiera conocer sobre los temas que trabajó Fontana encontrará allí una buena síntesis. La lectura de su artículo me ayuda a no meterme en esos berenjenales, ya que sin duda, él lo hace con mucha más propiedad que yo. 
Lógicamente matriculé con mi tutor Mercat i Nació, y gracias a la experiencia de la tutoría y de este curso, creció nuestra amistad. Una amistad que como todas ha conocido de altas y de bajas, de momentos de cercanía y momentos de alejamiento. En su curso pude aprender muchas cosas, pude entender la interrelación existente entre fenómenos como clase, mercado, estado y nación. Partiendo del caso español, nos dio un paseo por Europa, la bibliografía correspondía al idioma del país analizado, y así fuimos de Cataluña y España, a Francia, Reino Unido, Italia, Alemania y Rusia.

Sus clases eran magistrales, llegaba puntual con la clase preparada por escrito y exponía y exponía. Claro como él solo, siempre he dicho que para no entender sus argumentos uno tenía que ser bruto. Lo más complejo él lo sabía explicar en el lenguaje más llano y nunca humilló a un estudiante. En sus aulas comprobé lo que ya sabía, el aula es un espacio para construir conocimiento en conjunto, para ceder el lugar a quien sabe y para ser su soporte, para garantizar la libre expresión de las ideas en un ambiente de respeto, tolerancia y con espíritu constructivo y sólidamente fundamentado. Quien es grande no humilla a nadie, su lugar está asegurado, no necesita impresionar, su calidad humana y profesional no requiere de poses fingidas. No tiene que pisar ningún cuello para subir por la escalera.

Duro en la crítica, pero nunca malintencionado. Su actitud era la de un maestro. Criticaba para corregir, para forjar y formar buenos historiadores, buenos ciudadanos. Tenía claro cuál era su función dentro de la sociedad en la cual vivía, tenía muy claro cuál era el papel del historiador en la encrucijada mundial actual y para qué servía el análisis en perspectiva histórica. Lapidario como él solo, con una agudeza mental y con una sólida formación destrozaba enemigos y argumentos con una facilidad enorme y con un sarcasmo que le salía con elegancia. Aún recuerdo aquella tarde en una de nuestras primeras reuniones en donde pasábamos página de autores leídos y le cité a Phillipe Ariés, le hice ver mi distancia de su visión en torno a las cuestiones de mentalidad y me dijo "Cuando a mí me citan a Phillipe Ariés, es que yo me trepo como un gato por las paredes". Siendo franco, razones tenía para hacerlo. Tenía un espíritu de síntesis brutal y su análisis incluso preveía en muchas ocasiones lo que años después veíamos acontecer.

Lector empedernido, hijo de un viejo librero, su casa en el Nou de la Rambla, era un verdadero fortín donde se daba a leer y trabajar. Muchas veces le pillé trabajando un 31 de diciembre, cuando le llamé con motivo del año nuevo. Era una especie de cita anual, de costumbre por esas fechas. Meticuloso, veía y leía, lo que otros pasaban por alto, cosa que comprobé un día en un pasillo de la Autónoma cuando le encontré leyendo un libro gruesísimo, estaba revisando las reseñas, esas que están al final del libro y que casi nadie lee. Al encontrarme se detuvo y me preguntó “¿tú conoces esta obra?”, le respondí que sí. Venía leyendo 
una reseña de Costa Rica before coffe, de Lowell Gudmundson. Dirigía una tesis doctoral sobre historia social del crimen, en un país lejano llamado Costa Rica y él tenía que leer lo que allí se producía.

Era un ser humano como todos, lleno de virtudes y defectos. ¿Quién no los tiene? Que levante la mano el que esté libre de ellos. Fanático Culé, en la clase del martes a las 4 de la tarde, se sabía si el F.C. Barcelona en cualquiera de sus ramas había ganado, empatado o perdido en la jornada anterior. Conocía el ir y venir de todos en la ciudad barcelonesa y le contaba a uno en conversaciones de sobremesa, la vida y milagros de cada quien. Nadie escapaba a su repaso social. Tenía fe en sus estudiantes, una esperanza absoluta de que cada quien un día daría lo mejor de sí. No olvido haberle oído decir eso una tarde en una charla que dio en Terrasa. Sabía guardar silencio y tomaba una actitud de aprendiz cuando asumía que no conocía de un tema y dejaba hablar a quién él reconocía como especialista.

Defensor mesurado de la catalanidad, crítico con los sucesos recientes, pero abierto a dar su clase en "la lengua del imperio" dado que en su clase estábamos dos estudiantes de América Latina. Un marxista que supo guardar una postura crítica, tanto ante la extinta Unión de las Repúblicas Socialistas Soviéticas y su social expansionismo, como ante el imperialismo estadounidense y el de sus aliados. Una lectura de sus últimos libros Por el bien del imperio. Una historia del mundo desde 1945, El futuro es un país extraño y El siglo de la revolución. Una historia del mundo desde 1914, dejan claro este punto.

No le gustaba para nada dejar cabos sueltos. Recuerdo una conversación a finales de septiembre, inicios de octubre de 1988, en Plaza Cataluña, en la que me decía que pese a haber presentado su tesis doctoral en 1962, sentía que no la había terminado, que aún tenía cosas que trabajar en torno a la misma. Esa actitud quedaría reflejada en su comentario aparecido en El futuro es un país extraño. Una reflexión sobre la crisis social de comienzos del siglo XXI cuando dice:

\footnotetext{
"Este libro nace de las preocupaciones que me surgieron tras haber concluido Por el bien del Imperio. La profundización de la crisis y, sobre todo, el carácter que tomó al extenderse por Europa, ha sacado a la luz la dura realidad de lo que, más allá del retroceso económico, se presenta en la actualidad como una grave crisis social, cuyos rasgos más visibles son la privatización de la política, primero, y la del propio estado más adelante, con la formación paralela de un sistema represivo capaz de prevenir y contener la protesta pública". ${ }^{3}$
}

3 Josep Fontana i Lázaro, El futuro es un país extraño. Una reflexión sobre la crisis social de comienzos del siglo XXI (Barcelona, España: Ediciones Pasado y Presente, 2013). Una muestra más de este deseo de no dejar nada en el aire y aclarar lo que él consideraba que tenía que quedar claro queda manifiesto cuando en el prólogo de La historia de los hombres: el siglo XX apunta lo siguiente: "Cuándo acabé de escribir La Historia de los hombres, hace algo más de un año, me di cuenta de que se trataba en realidad de dos libros distintos: un ensayo de historia de la historiografía desde los orígenes hasta el siglo XX y un análisis crítico de las corrientes historiográficas actuales, con algunas propuestas para la reconstrucción de una 
Una actitud similar la mostraría en otra de sus últimas obras De en medio del tiempo. La segunda restauración española (1823-1834). En su introducción nos enseña que sobre los viejos temas se tiene que volver una y otra vez:

\begin{abstract}
“...este libro forma parte de un proyecto que inicié hace unos treinta y cinco años con la intención de investigar «la crisis del Antiguo Régimen español», de acuerdo con la visión que acostumbra a designar con esta expresión el paso de las viejas sociedades europeas a las nuevas explicándolo como el transito del absolutismo al estado liberal y de la economía «feudal» a la «capitalista», con abstracciones simplificadoras que se ajustan mal a una realidad mucho más compleja [...] Para completar este proyecto he ido publicando, a lo largo de los años, una serie de piezas separadas: La quiebra de la monarquía absoluta (1814-1820) (1971 y 2002), Hacienda y Estado en la crisis final del Antiguo Régimen español: 1823-1833 (1973), que era una especie de preparación especializada del volumen que hoy publico, dedicada en concreto a los problemas de la hacienda. La revolución Política y hacienda, 1833-1845 (1977) y La revolució liberal a Catalunya (2003). Se podría pensar, por consiguiente que este volumen cierra el proyecto. No es así por varias razones. La primera porque, con el paso del tiempo fui aprendiendo que no existía un único e inevitable camino del pasado al presente, sino una multiplicidad de posibilidades que el historiador debía explorar para conocer las rutas que llevaban como dijo T.S. Eliot en Burnt Norton por el corredor que no tomamos hacia la puerta que no abrimos". ${ }^{4}$
\end{abstract}

Lecciones magistrales las que aquí se nos dan, aflora su espíritu crítico incluso con sus propias viejas visiones y nos enseña acerca de la necesidad de estar constantemente a la luz de los nuevos avances, estar releyendo el pasado con la intención de descubrir nuevas rutas que nos permitan comprender y releer el presente.

¿Por qué esas idas y vueltas a sus temas del ayer? ¿Por qué esos retornos al pasado? Por la vigencia de las temáticas actuales de los temas allí tratados. Dicho en sus propias palabras:

nueva historia económica y social adecuada a las exigencias y a las necesidades de nuestro tiempo. Me propuse entonces desgajar esta segunda parte del libro, para poderla ofrecer a un tipo de lectores a quienes tal vez no interesara la primera. Lo he hecho tomando la parte que estudia la evolución de las corrientes historiográficas desde el fin de la primera guerra mundial, en 1918, hasta la actualidad y la he aligerado eliminando el extenso aparato de notas del original, tal vez demasiado extensas, y limitando las referencias bibliográficas a una lista final en la que se señalan, capítulo por capítulo, los libros más importantes que se han utilizado para escribirlo. He procurado, además, revisar y actualizar el texto -lo que explica que en la bibliografía figuren algunos libros no utilizados anteriormente- y hacerlo más legible". Josep Fontana i Lázaro, La historia de los hombres: el siglo XX (Barcelona, España: Editorial Crítica, 2010). Destaco de esta cita su actitud de autocrítica en relación a una de sus propias obras y el deseo de poder ser accesible a un público que sin ser historiador le gusta leer libros de historia.

4 Josep Fontana i Lázaro, De en medio del tiempo. La segunda restauración española (1823-1834) (Barcelona, España: Editorial Crítica, 2013), 9-10. 
"La conclusión es que debería, si me quedan tiempo y fuerzas para hacerlo, acabar esta investigación con una especie de visión general que plantease los complejos procesos de la transformación de las sociedades europeas entre los años 1814 y 1848, desde el inicio de la restauración hacia la frustración final de las esperanzas revolucionarias, en un intento de explorar los distintos corredores de la historia y mirar detrás de las puertas que los vencidos de ayer no pudieron abrir. No para lamentar las viejas derrotas, sino para entender mejor por qué se produjeron". 5

El resaltado es mío y me permite enlazar con otro tema. Soberana lección de historia, de la utilidad del saber histórico y del por qué del oficio de historiador. Desde sus primeras obras le preocupaba mucho dejar en claro, cuál era el papel que le tocaba jugar al historiador en medio de la sociedad en que vivía. A veces lo hacía desde una óptica muy historiográfica, "haciendo uso del oficio" como cuando dijo:

"Entre cuantos se ocupan del oficio del estudio de la sociedad, el historiador se distingue por el hecho de que solo a él le incumben todas las dimensiones del hombre y todos los ritmos del tiempo: la evolución secular y la sucesión de los acontecimientos cotidianos, la lucha por la subsistencia y las aspiraciones colectivas. A otros investigadores, vecinos suyos en el trabajo, corresponde el análisis de la economía, de la organización administrativa o jurídica de la expresión artística... Al historiador toca dar una explicación global de los hechos humanos, por encima de cualquier compartimentación. Empleará para ello, entre otros materiales, los resultados que aportan otras disciplinas y puede usar también alguno de sus métodos para resolver problemas concretos que se asemejan a los que éstas plantean. Pero como su objeto más específico, la explicación global, no la comparte con nadie, solo podrá resolver sus problemas mayores por si mismo y con su propio instrumental metodológico". ${ }^{6}$

Comparto con él su visión de totalidad, y aunque diría que la misma no es exclusiva del historiador, sí lo es del análisis en perspectiva histórica. Punto interesante para abordar, pero que pienso excede lo que se me pidió en esta reseña. Esa preocupación por el estudio de la totalidad concreta y la crítica a una historia híper especializada, atomizada y casi en migajas fue retomada por otros historiadores y por él mismo en La Historia después del fin de la historia, crítica de las nuevas modas historiográficas que en su juicio hacían perder a la historia su visión de totalidad:

"Uno de los problemas más graves que nos plantea ese cambio de fundamentación, ese sometimiento al vasallaje de otras disciplinas sociales, es el de la fragmentación

$5 \quad$ Ibid, 10.El resaltado del texto es mío.

6 Josep Fontana i Lázaro, Cambio económico y actitudes políticas en la España del siglo XIX (Barcelona, España: Editorial Ariel, 1975), 5. 
de nuestro objeto de estudio. En la medida que cada una de estas «ciencias» tiene un objeto distinto al de la historia, que es el de abarcar la totalidad del cuadro social, su utillaje solo sirve para actuar sobre segmentos de este cuadro, lo cual ha tenido como consecuencia que una investigación tentada por el mimetismo cientifista se convierta en esa «historia en migajas» de la cual nos habla François Dosse y que es mucho menos de la vieja escuela de Annales, donde Braudel conservaba todavía el sentido de la globalidad, que esa otra nouvelle histoire que guarda escasa relación con aquella, que viene a ser algo así como una degeneración de la que en su día propugnaron Febvre y Bloch". ${ }^{7}$

En otras ocasiones su visión se politizaba más, nunca jugó al falso apoliticismo y dejaba claro que el quehacer del historiador tenía una vertiente y una connotación claramente política:

\begin{abstract}
"El papel del historiador es estas circunstancias históricas es de ayudar a denunciar la mentira de unos análisis tramposos que pretenden incitarnos a la resignación para contribuir, en la medida de sus fuerzas, a la tarea de reinventar un nuevo futuro, que es todavía un país desconocido, una vez arruinadas las posibilidades de realizar el viejo: el que tuvo su origen en las anticipaciones de la Ilustración y alentó nuestras esperanzas hasta el fin de las tres décadas expansivas que siguieron al término de la segunda guerra mundial". ${ }^{8}$
\end{abstract}

En L'ofici d'historiador, concretamente en el artículo "Per a què serveix un historiador?", se preocupa desde otros ángulos por el mismo punto, y señala la importancia de la enseñanza de la historia, y de eso que se ha dado en llamar la historia de uso público. El historiador debe estar allí, hacerse presente enseñando, orientando y poniendo al día el conocimiento histórico divulgado, recuperando la memoria. Por eso afirma:

\begin{abstract}
"Para los que nos seguimos considerando de izquierda -lo que para mí significa fundamentalmente que pensamos que existen muchas cosas que no están bien y que es necesario que luchemos por mejorarlas-, el estudio de la historia tiene que servirnos para combatir la desesperanza y re fundar la utopía, porque como se nos ha dicho «en un tiempo de resignación política y de cansancio, el espíritu utópico es más necesario que nunca»". ${ }^{9}$
\end{abstract}

Sin duda alguna, esa forma de entender su oficio, le convirtió en un ser humano interesado por el curso de los sucesos mundiales del siglo XX, y de lo que va del actual. Le tenía tomado el pulso a la situación mundial, y eso se ve a las claras, en las obras que en sus últimos años dedicó al siglo pasado y al actual.

7 Fontana i Lázaro, La historia después..., 81.

8 Fontana i Lázaro, El futuro es un país extraño..., 20.

9 Fontana i Lázaro, L'ofici d'historiador (Girona, España: Documenta Universitaria, LLiçons de la Cátedra Ferrater Mora, 2010). 
Años después de haberlas leído, al ver lo que estaba aconteciendo mundialmente, me pareció estarle leyendo nuevamente. En ellas se adelantó a lo que luego pasaría, fue visionario, supo leer el futuro. Su lectura del pasado y del presente, le permitió intuir lo que se vendría y eso es un mérito nacido de su trabajo serio, erudito y disciplinado y en ello reveló lo útil de su oficio de historiador. En estas obras, aunque muy centrado en Europa y los Estados Unidos, con referencias marginales a otras partes del mundo, América Latina entre ellas, pudo ver las tendencias generales del mundo que otrora dijo ser socialista y del orientado al capitalismo que realmente existe y da su explicación del por qué del fracaso de ambos y cómo se llegó a la situación actual. En su evaluación de los últimos cien años se nota un sesgo que algunos pueden tildar de pesimista, yo lo veo realista:

\begin{abstract}
"El progreso entendido como la suma del crecimiento económico y de una mejora colectiva de los niveles de vida, como consecuencia de un reparto equitativo de sus beneficios- que habíamos desalojado de su papel de motor de la historia, reaparecería al menos en el siglo XX y nos devolvía la esperanza en el futuro. El problema es que este cambio, que se habría iniciado a fines del siglo XIX y que tuvo su etapa más vigorosa en los treinta años que siguen al fin de la Segunda guerra mundial, terminó repentinamente hacia 1975 . Y no se ha recuperado en los últimos cuarenta años [...] La crisis de 2007-2008 empeoró aún más esta evolución en todos los sentidos. Pero el problema más grave al que nos enfrentamos hoy es el de explicar por qué, una vez pasada la crisis, prosigue cada vez con más fuerza esta dinámica de aumento de la desigualdad que conlleva el empobrecimiento de la mayoría". ${ }^{10}$
\end{abstract}

No profetiza la salida, pero sí deja ver que en este mundo creado por el capitalismo realmente existente, una vez vencido el socialismo realmente existente, densos nubarrones se ciernen sobre esta victoria y nos dice que hay movimientos incipientes, desorganizados, distintos de otros que le precedieron en el siglo pasado y que tienen a los jóvenes como actores centrales de la protesta:

\footnotetext{
“A lo cual hay que sumar el hecho de que, a diferencia de lo que sucedió en 1968, el sistema es ahora incapaz de integrarlos ofreciéndoles unas compensaciones adecuadas. Como los trabajadores de 1848, los jóvenes de esta nueva revuelta tienen muy poco que perder y un mundo que ganar. El futuro está en sus manos". ${ }^{11}$
}

\footnotetext{
¿Qué tan fuertes serán estos momentos en un futuro? ¿Cómo se organizarán y articularán los mismos? Pienso que todavía es muy temprano para opinar al respecto. Como se titula uno de sus libros aquí citados, El futuro es un país extraño, y como finaliza diciendo ahí: "La tarea más necesaria a la que debemos

10 Josep Fontana i Lázaro, El siglo de la revolución. Una historia del mundo desde 1914 (Barcelona, España: Editorial Crítica, 2017), 653-654.

11 Josep Fontana i Lázaro, Por el bien del Imperio. Una historia del mundo desde 1945 (Barcelona, España: Pasado y Presente, 2011), 976.
} 
enfrentarnos es la de inventar un mundo nuevo que pueda ir reemplazando al actual que tiene sus hora contadas". ${ }^{12}$ Coincido con él, si algo nos ha enseñado el pasado, es que por los viejos caminos no se llega a la sociedad más justa con la que muchos seguimos soñando. Hay que estar atentos, al signo de los tiempos, hay que ser más creativos. ¿Cuándo y cómo se llegará a esa sociedad? No lo sé, él tampoco lo sabía. Pero al igual que él creemos que de que llegará, ¡llegará! Cuando menos la esperemos, y que, como dijo el poeta "A lo mejor es rebelión y estás viniendo". ${ }^{13}$

Cierro aquí estos recuerdos mezcla de lecturas y momentos compartidos con este buen amigo. Amigo y maestro, al cual debo tanto en mi formación profesional y humana. Dejó su huella en mí como también la han dejado el Dr. Héctor Pérez Brignoli, el Dr. Ricardo García Cárcel, el Dr. Joan Bestard Camps. Todos ellos amigos personales.

Termino repitiendo que Josep fue un Maestro, y fue como tal para muchos, querido y odiado. ¿Qué maestro no genera estas posiciones? Esta es mi visión de él, habrán otras, cada quien tendrá la suya, las respeto, pero esta, es la mía. En lo que a mi generación respecta y a muchas otras que nos siguieron, en Costa Rica, por su labor editorial pudimos conocer el pensamiento de autores de diversas partes del mundo, y estar al tanto de los avances de nuestra disciplina. En lo personal estoy en deuda con él, sé que volveremos a encontrarnos con otros rostros y en medio de otras sociedades y condiciones, las cuales no dudo ya no serán lo inciertas que hoy son y se vislumbran. ¡Serán mejores!

La Aurora de Heredia, Costa Rica

9 de septiembre de 2018

12 Fontana i Lázaro, El futuro es un país extraño..., 153.

13 Tomo este fragmento del poema Ché de la autoría de Humberto Constatini Cfr. Poemas al Ché (La Habana, Cuba: Instituto del Libro, 1969), 155. 